\title{
Gene expression profile favoring phenotypic reversion: a clue for mechanism of tumor suppression by NF-IL6 3'UTR
}

Ding Gan Liu ${ }^{1}$, Qiu Hong Jiang ${ }^{1}$, Yun Yi Wei ${ }^{1}$, Li Sun ${ }^{1}$, Bei Bei Fu ${ }^{1}$, Fu Kun Zhao ${ }^{2}$, Qiong Zhou ${ }^{1}$

Cell Research (2008) 18:325. doi:10.1038/cr.2008.23; published online 4 February 2008

Correction to: Cell Research (2003) 13:509-514. doi: 10.1038/sj.cr.7290195

In Figure 1B of this short communication, the legends for the vertical axis should be "Relative cell numbers". The corresponding author is sorry for this error.

The corrected Figure 1B is as follows:

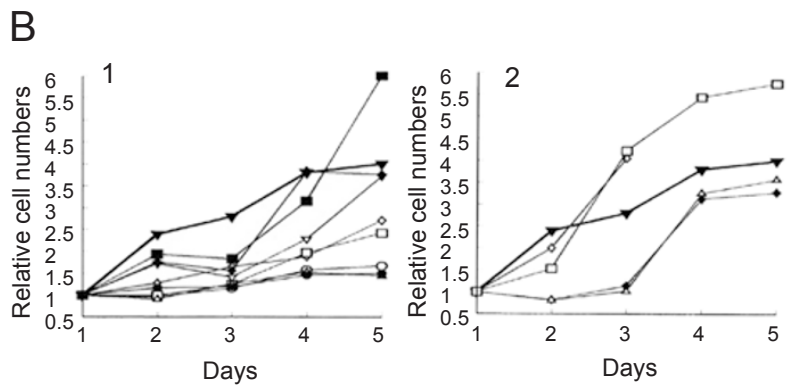

